\title{
Maternal age, length, and weight influence larval characteristics and viability in the viviparous temperate reef fish Helicolenus percoides
}

\author{
S. Kolodzey*, S. R. Wing, L. M. Durante \\ Department of Marine Science, University of Otago, PO Box 56, Dunedin 9054, New Zealand
}

\begin{abstract}
Mature age structure has been recognized as an important determinant of fecundity in fish populations. More recently it has been demonstrated that in some species, older, larger females can produce faster-growing and more viable larvae than younger, smaller females. We investigated this effect in sea perch Helicolenus percoides and collected information on fecundity as well as notochord length and oil globule volume (OGV) of larvae on the day of parturition, time to $50 \%$ mortality, and rate of change in length and OGV of cohorts of larvae in fed and unfed treatments. Absolute fecundity increased proportionally with maternal age and total length. Older, larger females produced cohorts of larvae with larger OGVs. These cohorts also had faster positive rates of change in length in the fed treatment than did cohorts of larvae produced by younger, smaller females. The OGV was positively correlated with rates of change in length and survival in the fed treatment; however, we did not detect influences on growth or survival in the unfed treatment. Further, cohorts of larvae in the unfed treatment had negative rates of change in length and lower survival compared to cohorts in the fed treatment. The results indicated that the OGV, which was affected by maternal age and size, was an important factor influencing larval growth and viability when external energy sources were available. These data provide insight into the reproductive biology of sea perch and highlight the importance of an old-growth age structure for effective larval viability and growth.
\end{abstract}

KEY WORDS: Maternal effects · Oil globule · Larval survival · Larval growth • Viviparity • Fecundity

\section{INTRODUCTION}

Over the past century, scientists have strived to understand the mechanisms that influence reproductive output and recruitment success of fish populations. Many theories, hypotheses, and models have been developed to calculate and predict spawning success and year-class strength for individual populations (Cushing 1972, Lasker 1975, Miller et al. 1988, Leggett \& Deblois 1994). Studies over the past 5 decades have demonstrated that larger, older fish can have distinctly different reproductive energetics than smaller, younger individuals (Hempel \& Blaxter 1967, Hislop 1988, Kjesbu 1989, Chambers \& Leggett 1996, Trip-

*Corresponding author: kolst069@student.otago.ac.nz pel et al. 1997). While recognition of the relationships between maternal condition and larval survival has been demonstrated in the literature since the 1960s (Nikol'skii 1962), we have only recently begun to incorporate these relationships into fisheries management considerations (Birkeland \& Dayton 2005). Currently, fisheries management is moving away from the population-based, single-species approach (Botsford et al. 1997), towards a multispecies fisheries management system, incorporating environmental and biotic factors, as well as variations in abundance, trophic structure, and demography within whole-fish communities (Pikitch et al. 2004, Beddington et al. 2007, Durante et al. 2020). As part of the approach,

() The authors 2021. Open Access under Creative Commons by Attribution Licence. Use, distribution and reproduction are unrestricted. Authors and original publication must be credited. 
population structure and maternal effects are now being recognized as important determinants of larval survival and recruitment success of marine populations (Hixon et al. 2014).

A large number of studies have demonstrated how age and size truncation of fish and invertebrate populations can affect the quality of offspring and recruitment (Longhurst 2002, Berkeley et al. 2004b, Birkeland \& Dayton 2005, Green 2008, Jack \& Wing 2010). In some species, a relatively small number of older, larger females can contribute disproportionally more to the reproductive output a population than younger, smaller females (Hixon et al. 2014). This is due to their abilities to have earlier and/or longer spawning seasons (Bobko \& Berkeley 2004, Wright \& Gibb 2005, Sogard et al. 2008), to produce multiple batches of eggs over extended periods of time (Parrish et al. 1986, Marteinsdottir \& Steinarsson 1998, Secor 2000), and to spawn in different locations (Wright \& Trippel 2009, Hsieh et al. 2010). For example, the positive effects of maternal age on the growth and survival of larvae was highlighted in a key experimental study on the black rockfish Sebastes melanops by Berkeley et al. (2004a). In this study, older mothers provisioned their offspring with larger oil globules, comprised of energy-rich fatty acid triacylglycerol, than did younger mothers. Consequentially, the larvae produced by older mothers had higher survival rates and grew 3 times faster than their counterparts produced by younger mothers (Berkeley et al. 2004a,b). The observed relationships highlight the critical links between adult demographics and recruitment dynamics in marine fishes.

Recruitment models that incorporate maternal traits such as age distribution, condition, fecundity, and variable spawning stock biomass (SSB) among years are better predictors of recruitment variation than models that simply rely on SSB (Marshall et al. 2003). While there are cases where the relationship between SSB or stock-recruitment (S/R) and the number of eggs produced has been demonstrated, uncertainty remains high for most fisheries models (Green 2008). The most common explanation for lack of an $\mathrm{S} / \mathrm{R}$ relationship is the high mortality during the larval period, estimated at up to $99.9 \%$ for free-swimming species (Ferron \& Leggett 1994). There is now evidence that, in many species, differences in larval survival can be linked to maternal effects (reviews by Green 2008, Hixon et al. 2014). Therefore, further quantifying species-specific differences in larval quality and survival due to maternal age and size is an important source of information for accurately estimating recruitment from SSB.
In the present study, we investigated maternal investment and larval survival in sea perch Helicolenus percoides (Richardson \& Solander 1842) from the Otago coast, New Zealand. Sea perch are a relatively small, long-lived, benthic species distributed throughout New Zealand and the southern Australian continental shelf and slope, where they have been caught from coastal regions to offshore seamounts and ridges in temperate waters at depths of $1000 \mathrm{~m}$ (Paul \& Horn 2009). Maximum lengths reported for sea perch from the East Coast of New Zealand's South Island range from $38 \mathrm{~cm}$ for females to $42 \mathrm{~cm}$ for males (Paul \& Horn 2009). Little is known about their movement and life history changes, although regional differences in colour, morphology, growth rates, and otolith microchemistry indicate that adult sea perch likely form discrete subpopulations (Paul \& Horn 2009, Smith et al. 2009, Lawton et al. 2010). The relatively sedentary lifestyle of adult sea perch highlights the importance of the larval stages for the maintenance of population connectivity.

Sea perch are viviparous, similar to other species in the family Sebastidae. Little is known about the reproductive biology of sea perch, and most of the available information is anecdotal. They release a gelatinous and buoyant mass that contains larvae that are approximately $2 \mathrm{~mm}$ long (Graham 1939). The larval mass dissolves in water to release free-swimming larvae (S. Kolodzey pers. obs.). There is little information on the functionality of the gelatinous mass or the process of parturition in sea perch. When extruded, larvae have a functional mouth, pigmented eyes, a loosely coiled gut, and a well-formed base and blade of the pectoral fin (Furlani 1997). By the time of extrusion, yolk sacs are fully absorbed by the larvae. An oil globule is present, visible as an orange to yellow sphere. The oil globule is the endogenous energy store, provided by the mother, that acts as a buffer from starvation in the first days of larval life before first feeding. Starvation during the initial larval phase is thought to be a major driver of larval mortality, which, along with predation and dispersal, contributes to recruitment variability in marine fishes (Anderson 1988, Huwer et al. 2011).

Understanding and identifying the factors that affect mortality and survivorship of fish larvae is crucial to gain insight into the mechanisms that regulate recruitment. Recent findings show that larval mortality is selective and that the phenotype of an individual has an effect on its survivorship (Johnson et al. 2014). In addition, mortality can vary among cohorts of larvae, contributing to large variations in recruitment (Johnson et al. 2014). Some laboratory and field studies have demonstrated that cohorts of faster- 
growing larvae had higher survival rates than cohorts of slower-growing larvae (Castro \& Cowen 1991, Houde 1997, Berkeley et al. 2004b, Dower et al. 2009). Higher larval survivorship has been attributed to stronger swimming capabilities and a shorter timeframe over which faster-growing larvae were exposed to size-dependent predation (Cowan et al. 1996, Dower et al. 2009). Accordingly, size is widely recognized as an important factor influencing larval survival (Anderson 1988, Garrido et al. 2015). For example, a larger size at hatch or extrusion is associated with a higher probability of survival (Vigliola \& Meekan 2002) due to increased performance-related traits such as growth, escape ability, and increased success in capture of prey (Miller et al. 1988, Fisher et al. 2007). Nevertheless, in some viviparous species, there is a context-dependent trade-off between the larval size and the energy reserves in the oil globule, indicating that larval size alone might be an insufficient measure of fitness (Fisher et al. 2007).

To gain a better understanding of the reproductive biology of sea perch, we investigated the relationships between maternal age, total length, weight, condition index (Fulton's $K$ ), and fecundity. We hypothesized that absolute and weight-specific relative fecundity would be higher among older, larger, females. Further, we investigated the relationships between maternal traits and the larval notochord length and oil globule volume (OGV) on the day of parturition, hypothesizing that older, larger, better-conditioned females would produce cohorts of larvae with larger notochords and larger OGVs than smaller, younger, less well conditioned females. We used a fed and unfed experimental design to compare larval viability traits; rate of change in length, rate of change in size of the OGV, and time to $50 \%$ mortality. We hypothesized that, in both treatments, cohorts of larvae from older, larger females would survive longer and be more viable than cohorts of larvae produced by younger, smaller females. The test of these hypotheses directly informed our understanding of relationships between maternal traits and larval viability, providing an important example relevant to understanding how adult population structure and demographics influence the larval stage of fishes.

\section{MATERIALS AND METHODS}

\subsection{Collecting and maintaining adult sea perch}

Adult sea perch were collected off the coast of Otago, New Zealand $\left(46^{\circ} 1^{\prime} 52.4^{\prime \prime} \mathrm{S}, 170^{\circ} 33^{\prime} 35^{\prime \prime} \mathrm{E}\right)$ dur- ing the Austral late spring/early summer in November 2015 ( $n=10)$, November and December 2017 ( $\mathrm{n}=$ 25), and December $2018(n=9)$ from a depth range of 20-60 $\mathrm{m}$ using hook and line fishing. Late spring to early summer is reported to be the primary parturition season for sea perch, with females carrying developed larvae (Paul \& Francis 2002). At the time of the study, there was no information on when internal fertilization occurs for sea perch in New Zealand waters. In south-eastern Australian waters, mating has been observed to occur from June to August (Park 1994).

Live fish were transported to the Portobello Marine Laboratory, Dunedin, New Zealand, where they were transferred into individual $70 \mathrm{l}$ tanks. The tanks were connected to the laboratory seawater circulation system, receiving seawater from the Otago Harbour. The holding time of females in the laboratory ranged from 3 to $12 \mathrm{~d}$ prior to parturition. During this time the water temperature ranged from 13.6 to $16.0^{\circ} \mathrm{C}$ in 2015, from 15.4 to $17.1^{\circ} \mathrm{C}$ in 2017 , and from 15.7 to $18^{\circ} \mathrm{C}$ in 2018 . Maternal females were not fed while held in the laboratory.

Immediately after parturition, the females were humanely euthanized under the University of Otago ethics protocols ET77/15 (2015 and 2017) and AUP18-193 (2018). For euthanasia, fish were transferred into a $150 \mathrm{mg} \mathrm{l}^{-1}$ Aqui-S solution for $40 \mathrm{~min}$ (Aqui-S New Zealand LTD 2016). Fish were then stored in a $-20^{\circ} \mathrm{C}$ freezer before further analysis of age, size, and weight.

\subsection{Maternal traits}

Age (yr), weight (g) of thawed fish, and total length $(\mathrm{mm})$ were recorded for each female. A condition index (Fulton's $K$ ) was calculated:

$$
K=\left(\frac{\mathrm{WW}}{\mathrm{TL}^{3}}\right) \times 10^{4}
$$

where WW is the wet weight $(\mathrm{g})$, and TL is the total length $(\mathrm{mm})$ of each female.

The sagittal otoliths were removed by cranial dissection to determine the age of each female. Otolith banding for sea perch was age validated by Paul \& Francis (2002). Otoliths were rinsed in deionized water and transferred to sterile Eppendorf tubes. One of each pair of otoliths was embedded in K36 epoxy resin (Epoxy Kit, Nuplex Industries) and transverse sections ( $\sim 1.5 \mathrm{~mm}$ thickness) were cut through the primordium using a Buehler Isomet low-speed diamond-bladed saw. The sections were mounted on 
glass slides using Crystalbond 509 (Amerco Products). The otoliths were then ground using wet-dry sandpaper (grades P600 and P800) until the growth increments were clearly visible. The slides were polished using ultrafine sandpaper (grade P1500) in combination with alumina silicate polishing powder. Ages were estimated from photomicrographs of sectioned otoliths under transmitted light. Only opaque zones (winter growth) bordered by translucent zones (summer growth) on both sides were counted. Image-processing software (ImageJ) was used to improve contrast and clarity of images and allow a more accurate reading of the annual growth increments.

\subsection{Larval rearing}

For growth and survivorship analysis, larvae from the same mother were used for fed and unfed experimental treatments. Approximately 500 larvae were stocked in 81 tanks divided by the presence and absence of marine rotifers, comprising the fed (3 rotifers $\mathrm{ml}^{-1}$ ) and unfed (0 rotifers $\mathrm{ml}^{-1}$ ) treatments. Rotifer cultures were fed with phytoplankton (Nannochloropsis sp.) (Nanno 3600, Reed Mariculture). The rotifer densities in the tanks of the fed treatment were monitored and adjusted every day to maintain the targeted food concentrations. Dead larvae were carefully removed from the bottom of the tank via a small suction tube. Larvae were reared in a controlled temperature (CT) room. The temperature was kept at $15^{\circ} \mathrm{C}$, and a natural day:night (12:12 h) cycle was applied. The rearing tanks were not connected to the seawater system; therefore, 2.51 of filtered seawater were exchanged manually every second day to ensure adequate oxygen saturation. The water temperature in the larval tanks was kept at a constant $15^{\circ} \mathrm{C}$, and the water that was used for the water exchange was kept in the CT room at a constant temperature of $15^{\circ} \mathrm{C}$.

\subsection{Fecundity}

After separating the larvae that were used for the feeding experiments ( 1000 larvae per female), the remaining larvae were removed from the tank and preserved in $2 \%$ seawater-buffered formalin (37\% formaldehyde). Using a plankton splitter, the larvae were separated into subsamples to estimate fecundity for each female. Two subsamples were counted, and the average was taken and multiplied by the division factor to estimate the absolute fecundity as the number of larvae that a female produced. The number of larvae removed from the tank for viability experiments was added to this number to obtain total fecundity estimates. Absolute fecundity $\left(\mathrm{F}_{\mathrm{abs}}\right)$ was described by a power function:

$$
\mathrm{F}_{\mathrm{abs}}=\mathrm{aMT} \mathrm{MT}^{b}
$$

where MT is the maternal trait (age, total length, wet weight, or condition index). Parameters $a$ and $b$ are the intercept and slope. To fit a regression to the data, the equation was log transformed:

$$
\log \left(\mathrm{F}_{\mathrm{abs}}\right)=\log (a)+b \times \log (\mathrm{MT})
$$

Weight-specific relative fecundity (larvae $\mathrm{g}^{-1} \mathrm{WW}$ ) was calculated by dividing absolute fecundity by maternal weight, and was best described as a linear function:

$$
\mathrm{F}_{\text {rel }}=a+b \times \mathrm{MT}
$$

\subsection{Larval characteristics and viability}

On the day of parturition, initial samples of approximately 20 larvae were taken and preserved in $2 \%$ seawater-buffered formalin (37\% formaldehyde) (Fig. 1). From both the fed and unfed treatments, sam-
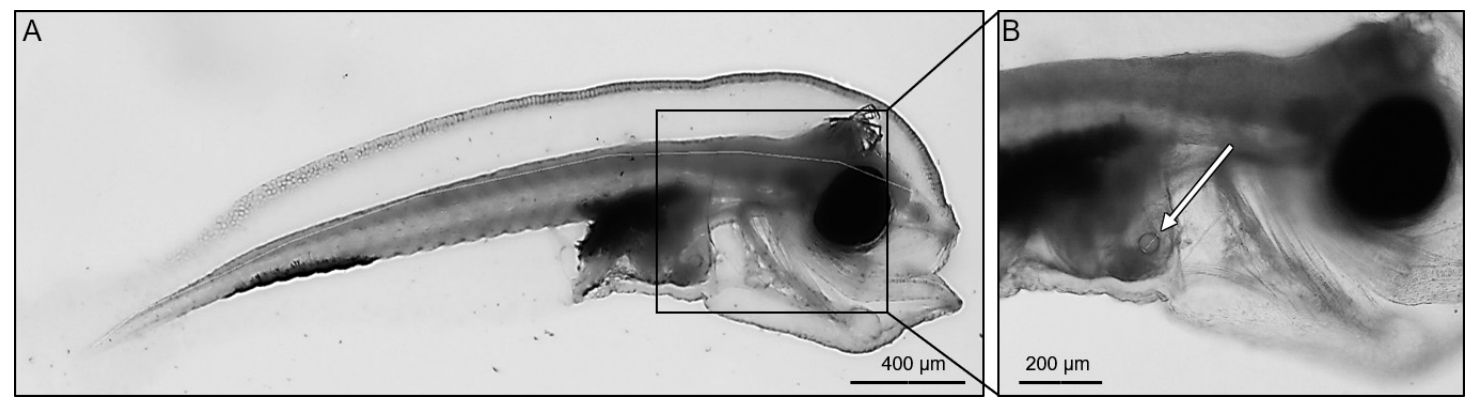

Fig. 1. Helicolenus percoides larva (A) on the day of parturition with (B) a close up of the head with a visible oil globule (white arrow) 
ples of 15 larvae were taken every second day and preserved in $2 \%$ seawater-buffered formalin $(37 \%$ formaldehyde) to later estimate larval viability as the rate of change in length of cohorts of larvae and change in average OGV. The larval characteristics notochord length $(\mu \mathrm{m})$ and oil globule diameter $(\mu \mathrm{m})$ were measured using photomicrographs of the larvae. Change in length was estimated using a linear regression model:

$$
L_{t}=a+b \times t
$$

where $L_{t}$ is the estimated notochord length ( $\left.\mu \mathrm{m}\right)$ at time $(t), a$ is the $y$-axis intercept, and $b$ is the change in size $\left(\mu \mathrm{m} \mathrm{d} \mathrm{d}^{-1}\right)$. It was assumed that the oil globule was a sphere. Therefore, the diameter $(d)$ was used to calculate the OGV as:

$$
\mathrm{OGV}=1 / 6 \pi \times d^{3}
$$

The OGV was $\log _{10}$ transformed to achieve a normal distribution. The rate of change of the average $\log _{10} \mathrm{OGV}$ was calculated using a first-order decay kinetic model:

$$
y=a_{t} \times \mathrm{e}^{(-k t)}+a_{0}
$$

where $a_{t}$ is the $\log _{10} \mathrm{OGV}$ at time $t,-k$ is the rate of change in the size of $\log _{10} \mathrm{OGV}$ over $t$, and $a_{0}$ is the $\log _{10} \mathrm{OGV}$ at $t=0$. The time to $50 \%$ mortality in the fed and unfed treatments was estimated as the time at which $50 \%$ of the initial number of larvae remained in the rearing tanks.

\subsection{Statistical analysis}

To test if temperature affected the notochord length and the OGV of cohorts of larvae, the temperature on the day of parturition $\left(\mathrm{T}_{\mathrm{P}}\right)$ and the mean temperature during the days that the female spent in the laboratory $\left(T_{M}\right)$ were included into a general linear model with the maternal trait predicting notochord length and OGV.

To test the hypothesis that older, larger, better-conditioned females were more fecund, the relationships between maternal age, total length, wet weight, and condition and absolute and weight-specific relative fecundity were analysed using linear regression. Change in length of cohorts of larvae, change in average OGV, and time to $50 \%$ mortality were compared between the fed and unfed treatments (treatment, fixed, 2 levels) using ANOVA. To test the hypothesis that maternal traits had an effect on change in length of cohorts of larvae, change in average OGV, and time to $50 \%$ mortality in the fed and unfed treatments, ANCOVA with the factors treatment (fixed, 2 levels) nested within a maternal trait (age, total length, or wet weight, continuous) was used. The relationship between larval notochord length and OGV on the day of parturition was analysed using linear regression. The hypothesis that larval characteristics on the day of parturition (notochord length and OGV) had an effect on the larval viability between the 2 treatments was tested using ANCOVAs with the factors treatment (fixed, 2 levels) nested within each larval characteristic (notochord length or OGV, continuous). All statistical analyses were performed using JMP Pro 11 (SAS Institute).

\section{RESULTS}

In 2015, the larvae of 10 females that ranged from 11 to $47 \mathrm{yr}, 257$ to $338 \mathrm{~mm}$ total length, and 289 to $667 \mathrm{~g}$ wet weight were sampled. The condition (Fulton's $K$ ) of these females ranged from 0.165 to 0.208 (Table 1). No larvae were used for feeding experiments in 2015. In 2017, 25 females were sampled that ranged from 8 to $26 \mathrm{yr}, 249$ to $310 \mathrm{~mm}$ total length, and 295 to $563 \mathrm{~g}$ wet weight (Table 1). The condition of the females sampled in 2017 ranged from 0.144 to 0.218 . Larvae of 6 females were used for feeding experiments in 2017. In 2018, 9 females were sampled that ranged from 8 to $28 \mathrm{yr}, 236$ to $311 \mathrm{~mm}$ total length, and 270 to $611 \mathrm{~g}$ wet weight. The condition of these females ranged from 0.178 to 0.215 (Table 1). Larvae of 9 females were used for feeding experiments in 2018. Generally, weight increased with maternal age and total length. Maternal length increased with maternal age, and the condition index decreased with increased maternal age and total length.

Table 1. Summary statistics for age, total length (TL), wet weight (WW), and condition index (Fulton's $K$ ) (mean $\pm \mathrm{SD}$ ) of female sea perch that spawned in the laboratory. The number of females $\left(\mathrm{n}_{\text {females }}\right)$, and the number of fed $\left(\mathrm{n}_{\mathrm{fed}}\right)$ and unfed $\left(\mathrm{n}_{\text {unfed }}\right)$ larval treatments are given

\begin{tabular}{|cccccccc|}
\hline Year & $\mathrm{n}_{\text {females }}$ & $\begin{array}{c}\text { Age } \\
(\mathrm{yr})\end{array}$ & $\begin{array}{c}\mathrm{TL} \\
(\mathrm{mm})\end{array}$ & $\begin{array}{c}\mathrm{WW} \\
(\mathrm{g})\end{array}$ & $\begin{array}{c}\text { Condition } \\
\text { index }(K)\end{array}$ & $\mathrm{n}_{\mathrm{fed}}$ & $\mathrm{n}_{\text {unfed }}$ \\
\hline 2015 & 10 & $23 \pm 9$ & $302 \pm 23$ & $510 \pm 117$ & $0.178 \pm 0.013$ & - & - \\
2017 & 25 & $16 \pm 4$ & $281 \pm 19$ & $430 \pm 85$ & $0.191 \pm 0.014$ & 6 & 6 \\
2018 & 9 & $16 \pm 6$ & $269 \pm 21$ & $405 \pm 99$ & $0.203 \pm 0.012$ & 9 & 9 \\
\hline
\end{tabular}




\subsection{Fecundity}

Absolute fecundity ranged from $\sim 14000$ to $\sim 31000$ larvae among females and generally increased exponentially with maternal age, total length, and wet weight (Fig. 2, Table 2). Weight-specific relative fecundity ranged from 40 to 60 larvae $\mathrm{g}^{-1} \mathrm{WW}$ and was analysed relative to maternal age, total length, and wet weight. None of the relationships was significant (Table 2).

\subsection{Maternal effects on larval notochord length and $\mathrm{OGV}$ on the day of parturition}

The $T_{P}$ and $T_{M}$ had no significant effects on the larval notochord length or the OGV on the day or partu- rition (Table 3) and were therefore excluded from further analyses. Maternal effects on the average larval notochord length on the day of parturition were not evident in the present study. However, older, larger, heavier females produced cohorts of larvae with a broader range of notochord lengths than younger, smaller females (age: $F_{1,42}=7.47, \mathrm{p}=0.0092$; total length: $F_{1,42}=11.23, \mathrm{p}=0.0017$; wet weight: $F_{1,42}=6.77, \mathrm{p}=0.0128$ ). Females with a higher condition index produced cohorts of larvae with significantly smaller ranges of notochord lengths $\left(F_{1,42}=\right.$ 4.93, $p=0.0319$ ) (Fig. 3). Similarly, older, larger, and heavier females also produced cohorts of larvae with larger oil globules (age: $F_{1,40}=6.45, \mathrm{p}=0.0151$; total length: $F_{1,40}=6.11, \mathrm{p}=0.0178$; wet weight: $F_{1,40}=$ 5.13, $p=0.0289$ ) (Fig. 4). There was no significant relationship between maternal condition index and

Table 2. Maternal age (A, years), total length $(\mathrm{TL}, \mathrm{mm})$, and wet weight (WW, g) effects on absolute fecundity ( $\left.\mathrm{F}_{\mathrm{abs}}\right)$ and weight-specific relative fecundity $\left(\mathrm{F}_{\text {rel, }}\right.$ larvae $\left.\mathrm{g}^{-1} \mathrm{WW}\right)$. Significant results $(\mathrm{p}<0.05)$ are highlighted in bold

\begin{tabular}{|c|c|c|c|c|c|c|}
\hline Dependent variable & Maternal trait & Equation & $r^{2}$ & $F$ & $\mathrm{p}$ & df \\
\hline \multirow[t]{3}{*}{ Absolute fecundity } & Age & $\log \left(F_{a b s}\right)=8.677+0.445 \times \log (A)$ & 0.63 & 11.70 & 0.0111 & 1,7 \\
\hline & Total length & $\log \left(F_{\text {abs }}\right)=-2.267+2.173 \times \log (\mathrm{TL})$ & 0.58 & 9.65 & 0.0172 & 1,7 \\
\hline & Wet weight & $\log \left(F_{a b s}\right)=5.032+0.813 \times \log (W W)$ & 0.73 & 18.89 & 0.0034 & 1,7 \\
\hline \multirow[t]{3}{*}{ Weight-specific relative fecundity } & Age & $\mathrm{F}_{\mathrm{rel}}=55.217-0.293 \times \mathrm{A}$ & 0.08 & 0.59 & 0.4654 & 1,7 \\
\hline & Total length & $\mathrm{F}_{\mathrm{rel}}=87.086-0.136 \times \mathrm{TL}$ & 0.21 & 1.91 & 0.2090 & 1,7 \\
\hline & Wet weight & $\mathrm{F}_{\mathrm{rel}}=58.797-0.019 \times \mathrm{WW}$ & 0.09 & 0.74 & 0.4191 & 1,7 \\
\hline
\end{tabular}
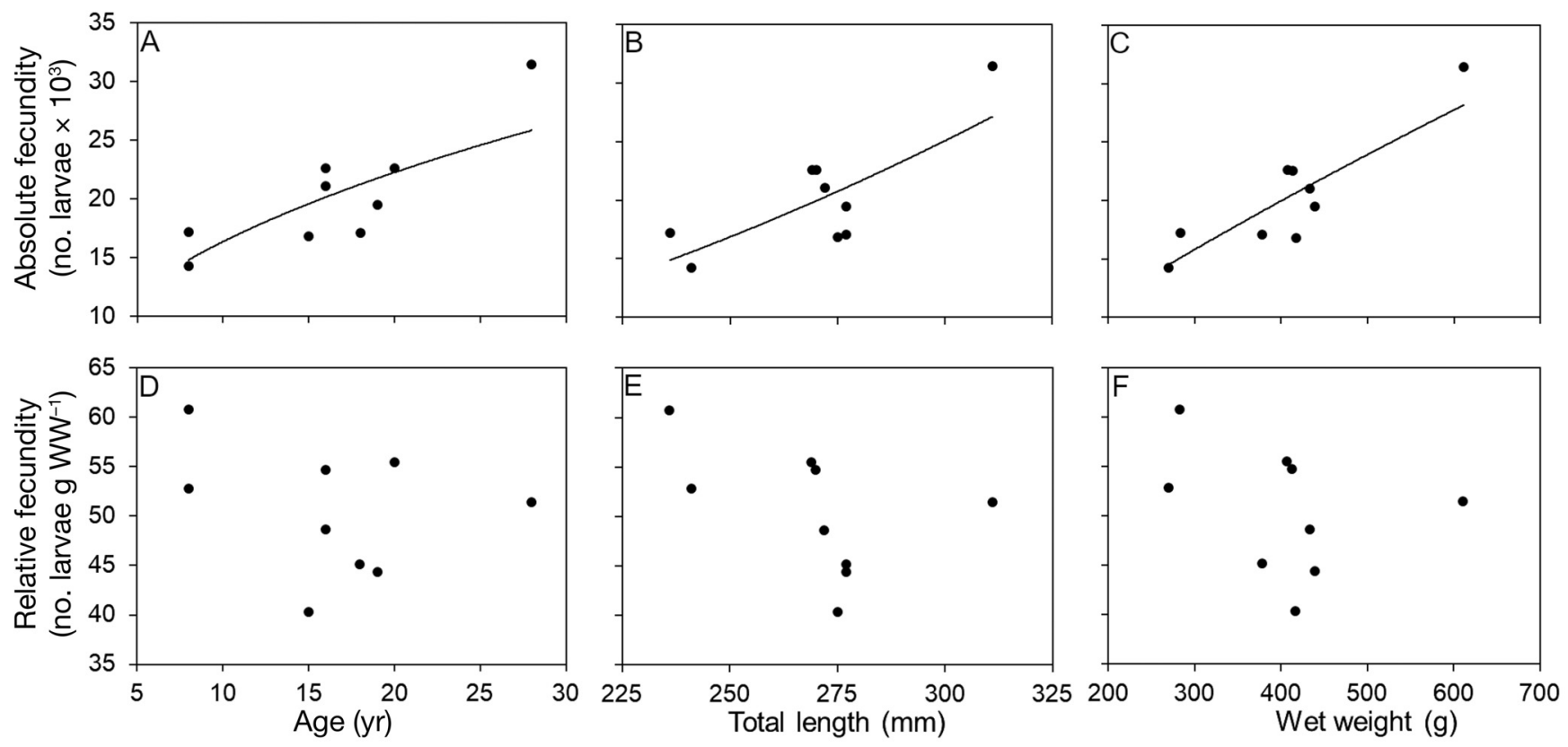

Fig. 2. Relationships between absolute fecundity (number of larvae produced by a female Helicolenus percoides, $\times 10^{3}$ ) and weight-specific relative fecundity (WW: wet weight) and $(A, D)$ maternal age, $(B, E)$ total length, and $(C, F)$ wet weight. Equations and regression results are given in Table 2. Regression lines are only shown for significant relationships 
Table 3. Effects of maternal traits (age, total length, wet weight), water temperature on the day of parturition $\left(T_{P}\right)$, and the average water temperature prior to the day of spawning $\left(\mathrm{T}_{\mathrm{M}}\right)$ on larval oil globule volume, notochord length, and the variance of the notochord length on the day of parturition. Significant results $(p<0.05)$ are in highlighted in bold

\begin{tabular}{|c|c|c|c|c|c|}
\hline $\begin{array}{l}\text { Dependent } \\
\text { variable }\end{array}$ & Model & $r^{2}$ & $F$ & $\mathrm{p}$ & $\mathrm{df}$ \\
\hline \multirow[t]{3}{*}{$\begin{array}{l}\text { Oil globule } \\
\text { volume }\end{array}$} & $\begin{array}{l}\text { Whole mode } \\
\text { Age } \\
\mathrm{T}_{\mathrm{P}} \\
\mathrm{T}_{\mathrm{M}}\end{array}$ & 0.19 & 3.03 & $\begin{array}{l}\mathbf{0 . 0 4 0 8} \\
\mathbf{0 . 0 0 7 3} \\
0.6050 \\
0.8393\end{array}$ & 3,38 \\
\hline & $\begin{array}{l}\text { Whole model } \\
\text { Total length } \\
\mathrm{T}_{\mathrm{P}} \\
\mathrm{T}_{\mathrm{M}}\end{array}$ & 0.19 & 3.06 & $\begin{array}{l}\mathbf{0 . 0 3 9 7} \\
\mathbf{0 . 0 0 7 0} \\
0.4182 \\
0.9531\end{array}$ & 3,38 \\
\hline & $\begin{array}{l}\text { Whole model } \\
\text { Wet weight } \\
\mathrm{T}_{\mathrm{P}} \\
\mathrm{T}_{\mathrm{M}}\end{array}$ & 0.17 & 2.60 & $\begin{array}{l}0.0658 \\
\mathbf{0 . 0 1 3 0} \\
0.4459 \\
0.9553\end{array}$ & 3,38 \\
\hline \multirow[t]{3}{*}{$\begin{array}{l}\text { Notochord } \\
\text { length }\end{array}$} & $\begin{array}{l}\text { Whole model } \\
\text { Age } \\
\mathrm{T}_{\mathrm{P}} \\
\mathrm{T}_{\mathrm{M}}\end{array}$ & 0.15 & 2.32 & $\begin{array}{l}0.0897 \\
0.8934 \\
0.5780 \\
0.1261\end{array}$ & 3,40 \\
\hline & $\begin{array}{l}\text { Whole model } \\
\text { Total length } \\
\mathrm{T}_{\mathrm{P}} \\
\mathrm{T}_{\mathrm{M}}\end{array}$ & 0.17 & 2.65 & $\begin{array}{l}0.0615 \\
0.3563 \\
0.6386 \\
0.1070\end{array}$ & 3,40 \\
\hline & $\begin{array}{l}\text { Whole model } \\
\text { Wet weight } \\
\mathrm{T}_{\mathrm{P}} \\
\mathrm{T}_{\mathrm{M}}\end{array}$ & 0.15 & 2.32 & $\begin{array}{l}0.0901 \\
0.9227 \\
0.5826 \\
0.1159\end{array}$ & 3,40 \\
\hline \multirow[t]{3}{*}{$\begin{array}{l}\text { Variance in } \\
\text { notochord } \\
\text { length }\end{array}$} & $\begin{array}{l}\text { Whole model } \\
\text { Age } \\
\mathrm{T}_{\mathrm{P}} \\
\mathrm{T}_{\mathrm{M}}\end{array}$ & 0.32 & 6.34 & $\begin{array}{l}\mathbf{0 . 0 0 1 3} \\
0.0609 \\
0.9035 \\
0.1414\end{array}$ & 3,40 \\
\hline & $\begin{array}{l}\text { Whole model } \\
\text { Total length } \\
\mathrm{T}_{\mathrm{P}} \\
\mathrm{T}_{\mathrm{M}}\end{array}$ & 0.37 & 7.89 & $\begin{array}{l}\mathbf{0 . 0 0 0 3} \\
\mathbf{0 . 0 1 0 7} \\
0.6337 \\
0.0749\end{array}$ & 3,40 \\
\hline & $\begin{array}{l}\text { Whole model } \\
\text { Wet weight } \\
\mathrm{T}_{\mathrm{P}} \\
\mathrm{T}_{\mathrm{M}}\end{array}$ & 0.32 & 6.41 & $\begin{array}{l}\mathbf{0 . 0 0 1 2} \\
0.0563 \\
0.6989 \\
0.0802\end{array}$ & 3,40 \\
\hline
\end{tabular}

the OGV on the day of parturition $\left(F_{1,42}=0.005, \mathrm{p}=\right.$ 0.9454) (Fig. 4).

\subsection{Larval viability comparison between fed and unfed treatments}

The mean $( \pm \mathrm{SE})$ rate of change in length of cohorts of larvae in the fed treatment was $9.94 \pm 3.46 \mu \mathrm{m} \mathrm{d}^{-1}$. In the unfed treatment, cohorts of larvae had a negative rate of change in length $\left(-27.19 \pm 2.58 \mu \mathrm{m} \mathrm{d}^{-1}\right)$.
The rate of change in length was significantly different between the 2 treatments $\left(F_{1,28}=73.97, \mathrm{p}<\right.$ 0.0001) (Fig. 5). The average rate of change in OGV was slower among cohorts of larvae in the fed treatment $(-0.10 \pm 0.004)$, ranging from -0.14 to -0.08 . In the unfed treatment, the average rate of change in OGV was $-0.12 \pm 0.008$, ranging from -0.17 to -0.07 . There was no significant difference in the rate of change in OGV between the 2 treatments $\left(F_{1,28}=\right.$ $3.27, \mathrm{p}=0.08$ ) (Fig. 5). The average time to $50 \%$ mortality was $11 \pm 0.47 \mathrm{~d}$ in the fed treatment and $9 \pm$ $0.18 \mathrm{~d}$ in the unfed treatment. Cohorts of larvae in the fed treatment lived significantly longer compared to larvae in the unfed treatment $\left(F_{1,24}=27.94, \mathrm{p}<\right.$ 0.0001) (Fig. 5).

\subsection{Maternal effects on larval viability}

Results of the ANCOVA demonstrated that the rate of change in length of cohorts of larvae was significantly affected by treatment $\left(F_{3,26}=92.59, \mathrm{p}<0.0001\right)$ and maternal age $\left(F_{3,26}=4.53, \mathrm{p}=0.0206\right)$. However, cohorts of larvae of older females grew faster only in the fed treatment ( $p=0.0085$ ) (Fig. 6). No effects of maternal age were found in the unfed treatment $(\mathrm{p}=$ 0.342). Similarly, results from ANCOVA demonstrated significant effects of treatment $\left(F_{3,26}=98.57\right.$, $\mathrm{p}<0.0001)$ and maternal total length $\left(F_{3,26}=5.66, \mathrm{p}=\right.$ 0.0091) on the rate of change in length of larval cohorts. Cohorts of larvae in the fed treatment had a faster rate of change in length when their mothers were larger $(p=0.0024)$. No effects of maternal total length were found in the unfed treatment $(\mathrm{p}=$ 0.8835) (Fig. 6). Maternal weight and treatment both significantly influenced the rate of change in length of cohorts of larvae (wet weight $F_{3,26}=4.38, \mathrm{p}=$ 0.0229 ; treatment $\left.F_{3,26}=91.84, \mathrm{p}<0.0001\right)$. Heavier females produced cohorts of larvae that had a faster rate of change in length than cohorts of larvae of lighter females in the fed treatment $(p=0.0065)$, but not in the unfed treatment $(p=0.8982)$ (Fig. 6).

There were no effects of maternal age $\left(F_{3,26}=2.83\right.$, $\mathrm{p}=0.077)$ or treatment $\left(F_{3,26}=3.70, \mathrm{p}=0.0653\right)$ on the rate of change in OGV (Fig. 6). ANCOVA results also showed no effects of maternal total length $\left(F_{3,26}=\right.$ 2.17, $\mathrm{p}=0.1345)$ and treatment $\left(F_{3,26}=3.55, \mathrm{p}=\right.$ 0.0708) on the rate of change in OGV (Fig. 6). Similarly, we found no effects of maternal wet weight $\left(F_{3,26}=2.79, \mathrm{p}=0.08\right)$ and treatment $\left(F_{3,26}=3.69, \mathrm{p}=\right.$ 0.0657 ) on the rate of change in OGV (Fig. 6).

The time to $50 \%$ mortality was longer in the fed treatment than in the unfed treatment, but maternal 

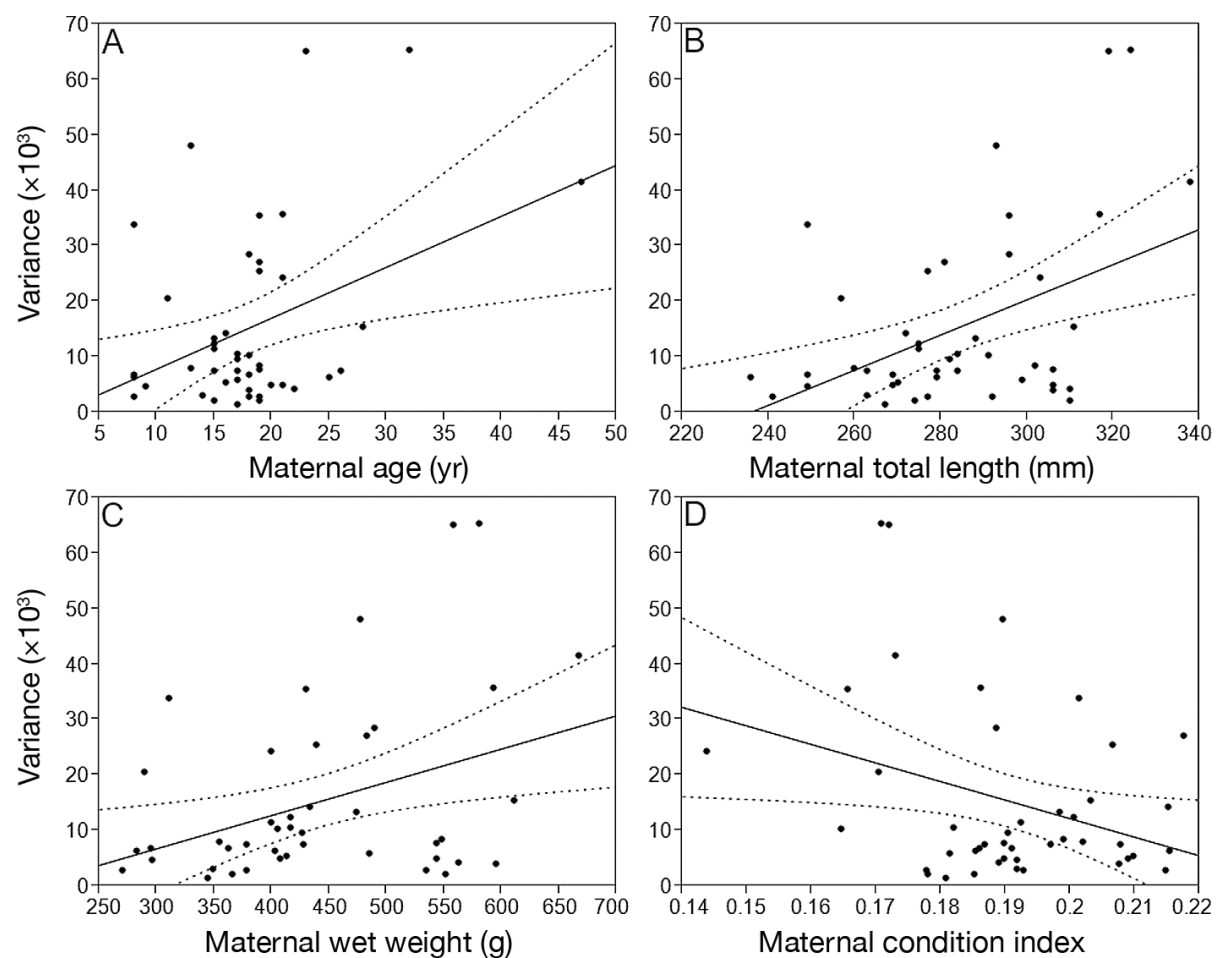

Fig. 3. Relationships between Helicolenus percoides maternal traits (A) age $\left(y=0.92 x-1.29, r^{2}=0.151\right)$, (B) total length $(y=$ $\left.0.32 x-74.73, r^{2}=0.211\right)$, (C) wet weight $\left(y=0.06 x-11.18, r^{2}=0.139\right)$, and (D) condition index $\left(y=-334.43 x+79.06, r^{2}=0.105\right)$ and the variance of the notochord length of a cohort of larvae $\left(\times 10^{3}\right)$ on the day of parturition. Regression lines are only fitted to significant relationships, dashed lines represent the $95 \%$ confidence intervals. Note the scaled $x$-axis
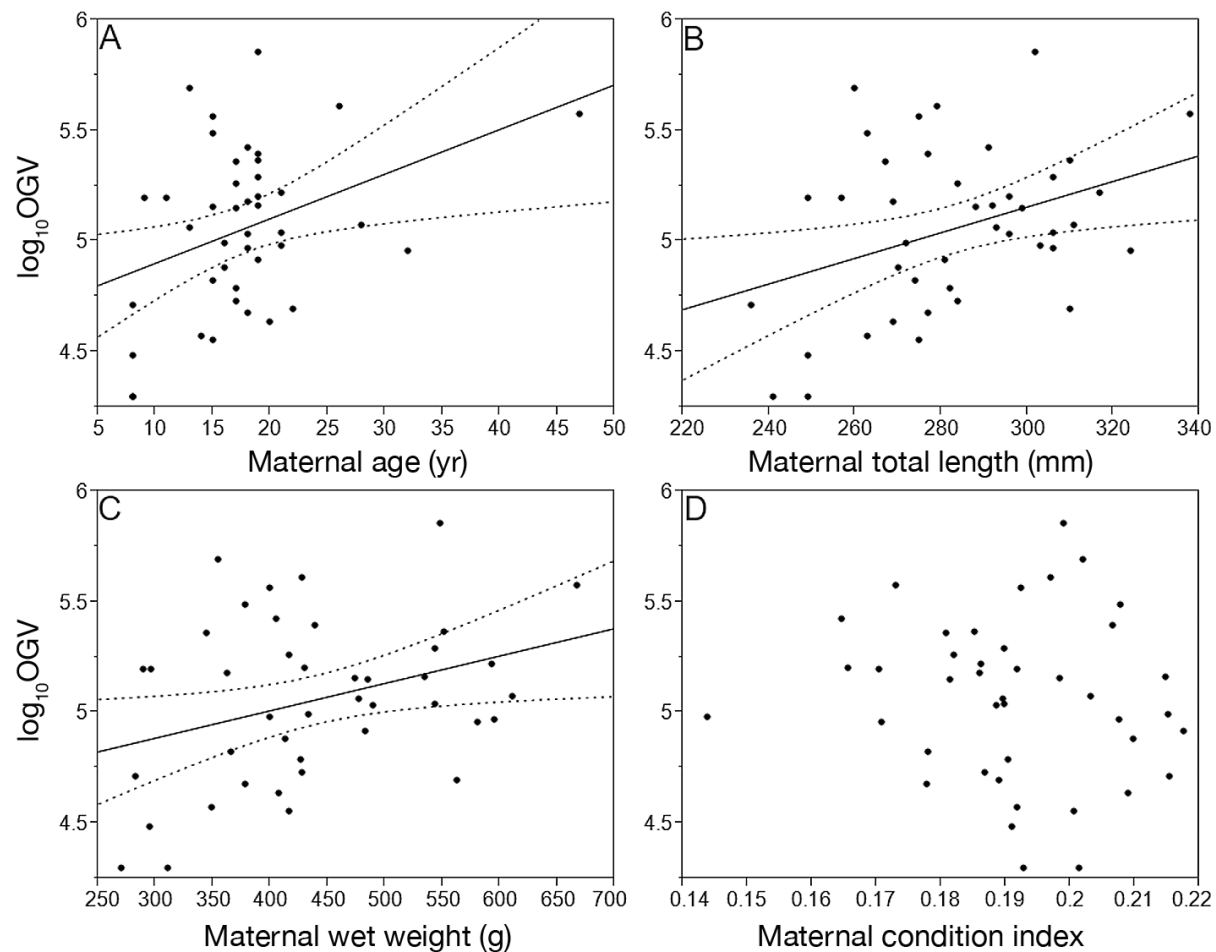

Fig. 4. Relationships between Helicolenus percoides maternal traits (A) age $\left(y=0.02 x+4.7, r^{2}=0.139\right)$, (B) total length $(y=$ $\left.0.006 x+3.42, r^{2}=0.132\right)$, (C) wet weight $\left(y=0.001 x+4.51, r^{2}=0.114\right)$, and (D) condition index and the average log ${ }_{10}$ oil globule volume (OGV) on the day of parturition. Regression lines are only fitted to significant relationships, dashed lines represent the $95 \%$ confidence intervals. Note the scaled $x$ - and $y$-axes 

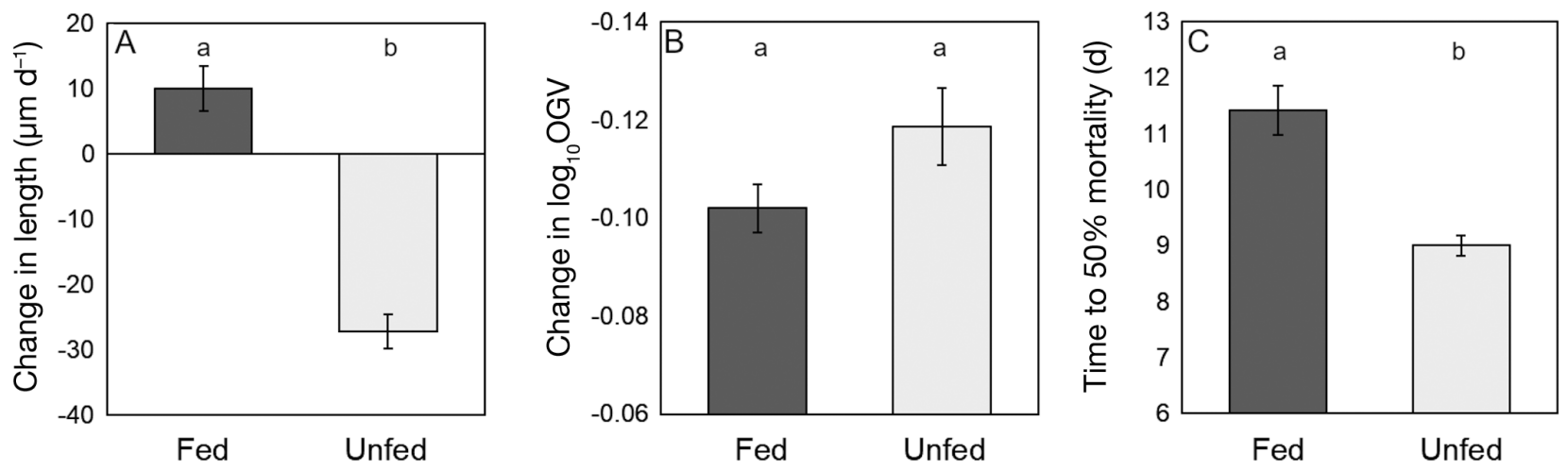

Fig. 5. Comparison of the mean $( \pm \mathrm{SE})(\mathrm{A})$ rate of change in length, $(\mathrm{B})$ rate of change in $\log _{10}$ oil globule volume (OGV), and

(C) time to $50 \%$ mortality between the fed and the unfed Helicolenus percoides treatments. Note the scaled $y$-axis
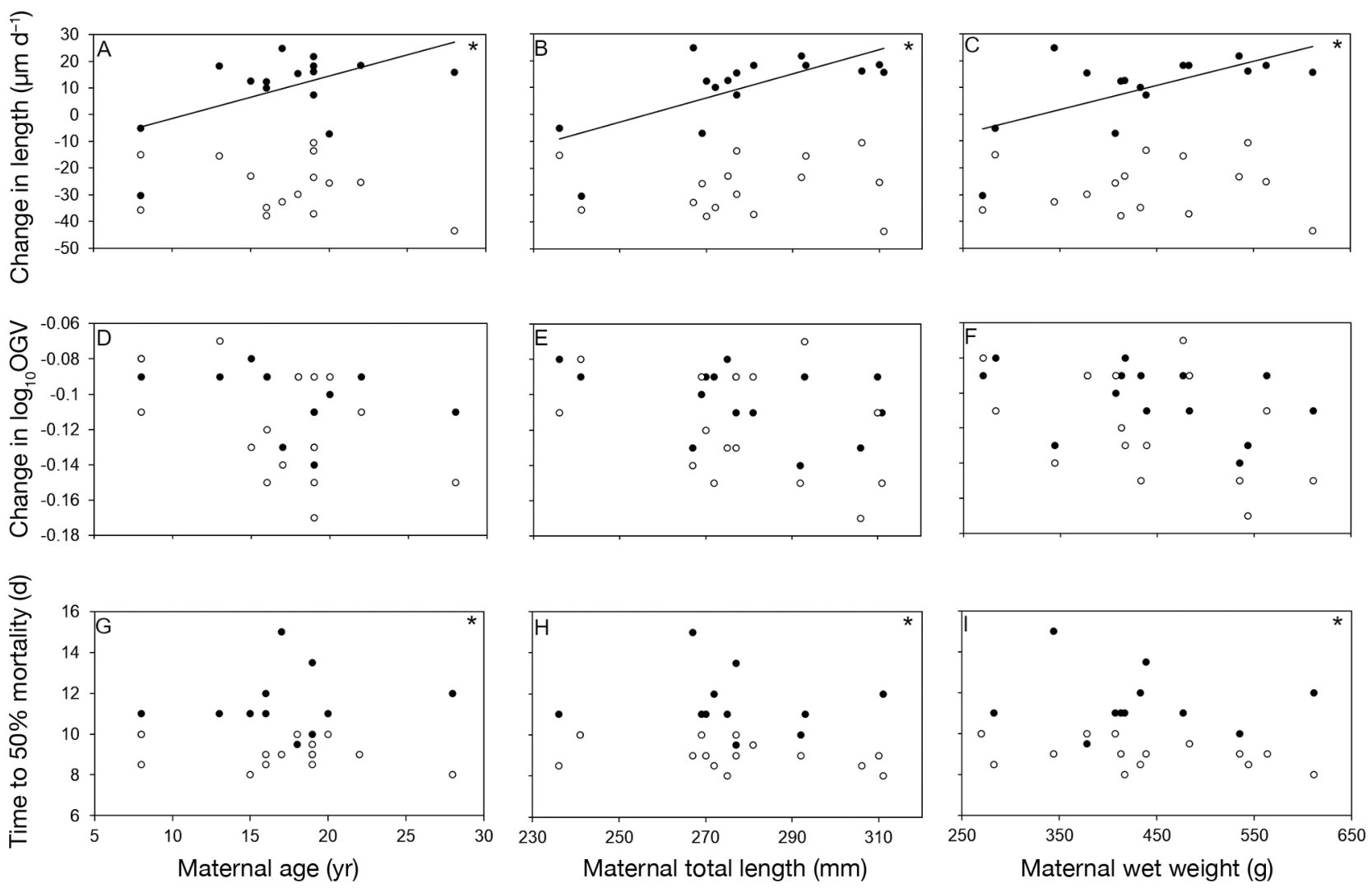

Fig. 6. ANCOVA results showing effects of the Helicolenus percoides maternal traits age, total length, and wet weight and the larval treatment (fed: black circles, solid lines; unfed: white circles) on larval (A-C) rate of change in length, (D-F) rate of change in $\log _{10}$ oil globule volume (OGV), and (G-I) time to $50 \%$ mortality. Significant relationships are indicated by a regression line; significant differences between the feeding treatments are indicated by an asterisk $\left({ }^{*}\right)$ in the upper right corner.

Note the scaled $x$ - and $y$-axes

age had no effect on larval survival (treatment: $F_{3,22}=$ $27.60, \mathrm{p}<0.0001$, maternal age: $F_{3,22}=0.71, \mathrm{p}=$ 0.5037) (Fig. 6). Similar results were found when the ANCOVA included maternal total length (treatment:
$F_{3,22}=25.89, \mathrm{p}<0.0001$, maternal total length: $F_{3,22}=$ $0.288, \mathrm{p}=0.7527$ ) and wet weight (treatment: $F_{3,22}=$ $25.74, \mathrm{p}<0.0001$, maternal wet weight: $F_{3,22}=0.351$, $\mathrm{p}=0.7078$ ) (Fig. 6). 

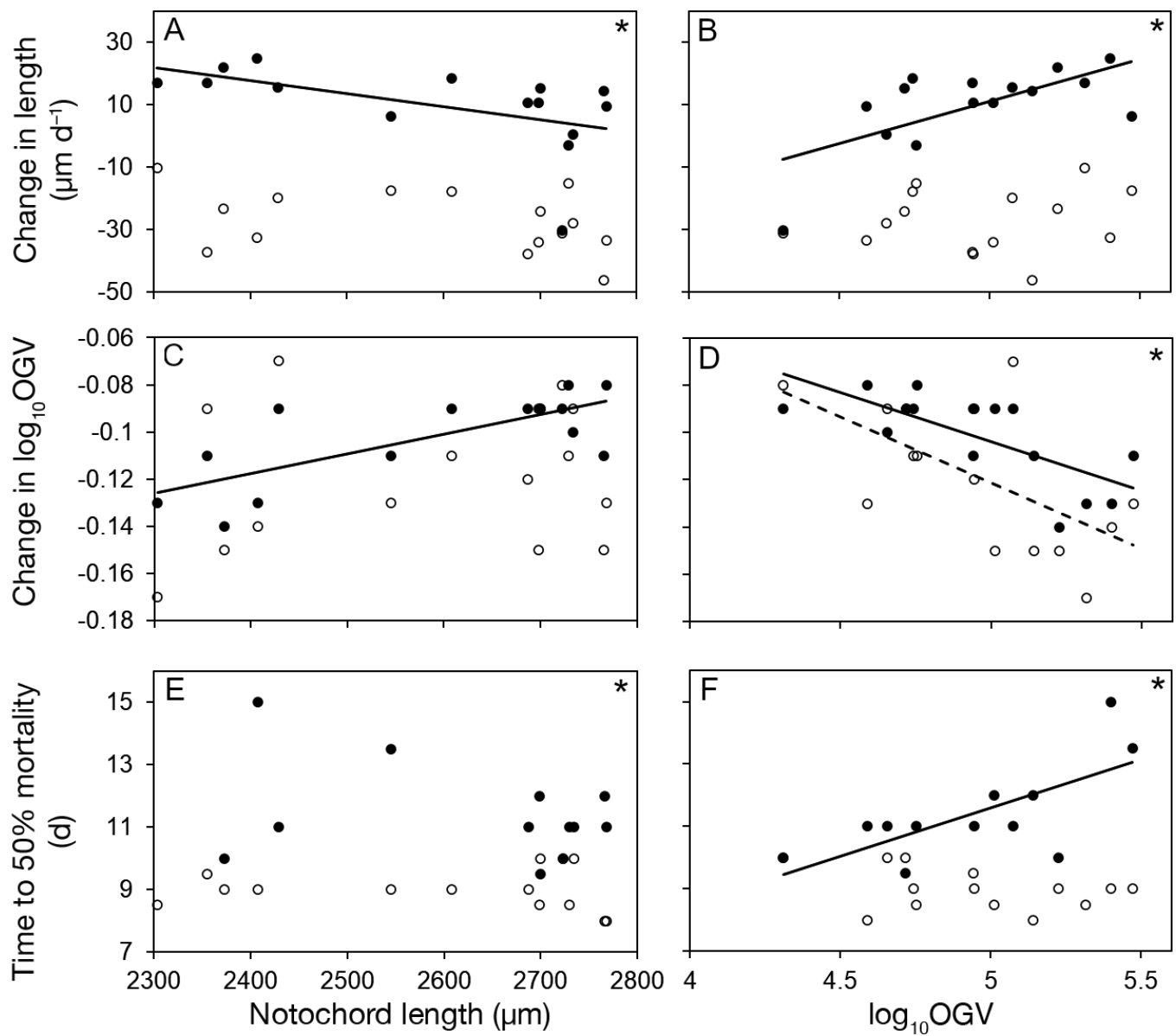

Fig. 7. ANCOVA showing the effects of Helicolenus percoides larval characteristics on the day of parturition (notochord length, $\log _{10}$ oil globule volume, OGV) and the larval treatment (fed: black circles, solid lines; unfed: white circles, dashed lines) on larval $(A, B)$ rate of change in length, $(C, D)$ rate of change in $\log _{10} \mathrm{OGV}$, and $(E, F)$ time to $50 \%$ mortality. Significant relationships are indicated by a regression line; significant differences between the feeding treatments are indicated by an asterisk $\left({ }^{*}\right)$ in the upper right corner. Note the scaled $x$ - and $y$-axes

\subsection{Larval effects on larval viability}

OGV in cohorts of larvae decreased with increasing notochord length on the day of parturition $\left(F_{1,42}=\right.$ 7.06, $\mathrm{p}=0.0111$ ). An ANCOVA demonstrated that the rate of change in length of cohorts of larvae was significantly influenced by notochord length on the day of parturition $\left(F_{3,26}=3.85, \mathrm{p}=0.0345\right)$ and treatment $\left(F_{3,26}=89.00, \mathrm{p}<0.0001\right)$. Cohorts of larvae born at a larger size had a slower rate of change in length than cohorts of larvae born at a smaller size in the fed treatment $(p=0.0206)$, but not in the unfed treatment ( $p=0.2150)$ (Fig. 7). The rate of change in OGV was not different between the fed and unfed treatments $\left(F_{3,26}=3.72, \mathrm{p}=0.0648\right)$. In the fed treatment, cohorts of larvae born at a larger size had a faster rate of change in OGV than cohorts of larvae born at a smaller size ( $p=0.0357)$, even though noto- chord length was not significant in the model $\left(F_{3,26}=\right.$ 2.89, p =0.0733) (Fig. 7). The time to $50 \%$ mortality was significantly longer in the fed treatment $\left(F_{3,22}=\right.$ 29.19, p < 0.0001); however, the notochord length on the day of parturition had no effect on larval survival in both treatments $\left(F_{3,22}=1.08, \mathrm{p}=0.3568\right)$ (Fig. 7$)$.

The rate of change in length was significantly faster among cohorts of larvae with larger oil globules $\left(F_{3,26}=5.26, \mathrm{p}=0.0121\right)$ and significantly different between the fed and unfed treatments $\left(F_{3,26}=\right.$ 96.46, p < 0.0001) (Fig. 7). There was no effect of the OGV on the rate of change in length of cohorts of larvae in the unfed treatment $(p=0.598)$. The rate of change in OGV was significantly faster among cohorts of larvae born with a larger $\operatorname{OGV}\left(F_{3,26}=9.12\right.$, $\mathrm{p}=0.001)$, in both the fed $(\mathrm{p}=0.0172)$ and unfed $(\mathrm{p}=$ 0.002 ) treatments (treatment; $F_{3,26}=5.17, \mathrm{p}=0.0314$ ) (Fig. 7). The time to $50 \%$ mortality was significantly 
longer in the fed treatment $\left(F_{3,22}=44.34, \mathrm{p}<0.0001\right)$. The OGV on the day of parturition also had a significant effect on the survival of larvae $\left(F_{3,22}=7.97, \mathrm{p}=\right.$ 0.0025). A larger OGV increased survival only in the fed treatment $(p=0.0008)$, but not in the unfed treatment ( $p=0.332$ ) (Fig. 7).

\section{DISCUSSION}

The results of the present study provide the first estimates of the relationship between absolute fecundity and maternal traits in sea perch, but not weightspecific relative fecundity. Previous anecdotal estimates of absolute fecundity have reported that 1 female, of indeterminate size, produced approximately 80000 larvae (Graham 1939). Our quantitative results demonstrated a significant positive relationship between absolute fecundity and maternal age, total length, and weight, which is consistent with observations of other species in the genus Helicolenus that had increased absolute fecundity with larger body and ovary sizes (Sequeira et al. 2015). Female fish may invest more energy in reproduction than somatic growth as they age, particularly in longlived species with low natural mortality (Roff 1992). Even though fecundity was higher among older, larger female sea perch in the present study, the fecundity-length relationship exponent $(b)$ was $<3$ $(b=2.173)$, and the fecundity-weight relationship exponent was $<1(b=0.813)$. These results indicated either that fecundity increased proportionally with length and weight, or that larger females were less fecund than expected in comparison with smaller females (Dick et al. 2017, Barneche et al. 2018). Further, our results demonstrated that while older, larger female sea perch did not produce more larvae per unit weight than younger, smaller females, the cohorts of larvae that older, larger females did produce were provisioned with larger oil globules and were more viable in a fed treatment than cohorts produced by younger, smaller females.

Older, larger females produced cohorts of larvae with a broader range of notochord lengths. The production of cohorts of larvae with a broader range of notochord lengths could be a bet-hedging strategy among older, larger females (Sasaki \& Ellner 1995). Different larval sizes have been associated with differences in their metabolic rates (Bochdansky et al. 2005, Garrido et al. 2015). In unpredictable environments with patchy prey and predator abundance, producing cohorts of larvae with variable metabolic rates may increase fitness and survival chances when facing variable environmental conditions (Bochdansky et al. 2005). In an extremely variable environment, such as the Otago shelf, where the distribution and abundance of suitable prey vary depending on local currents and winds (Murdoch 1989, Takagaki 2016, Stevens et al. 2019), producing larval cohorts with a broader range of notochord lengths and therefore metabolic rates may be favourable.

Cohorts of larvae produced by older and larger females were provisioned with larger oil globules than cohorts produced by younger, smaller females. Further, maternal effects on larval performance were evident in the rate of change in length of cohorts of larvae in the fed treatment. Older, larger, and heavier females produced cohorts of larvae that had faster positive rates of change in length than did cohorts of larvae produced by younger, smaller females. The average OGV had an important relationship with the rate of change in length and survivorship of cohorts of larvae in the fed treatment. Larval cohorts with larger oil globules had a faster rate of change in length than cohorts with smaller oil globules. The results indicated that when food was present, larger oil globules had important benefits for larval growth and viability. Larger oil globules were also associated with faster growth in multiple closely related rockfish species (Sebastes spp.) when food was not limited (Berkeley et al. 2004a, Fisher et al. 2007). In the present study, both growth and survivorship were not affected by OGV in the unfed treatment, indicating that OGV positively affected larval viability only in combination with adequate external energy resources at the time of first feeding. Our results provide evidence that older, larger females provisioned their larvae with larger oil globules on the day of parturition, which had significant benefits for larval viability in the fed treatment but not in the unfed treatment.

We observed significant differences in the rate of change in length of larval cohorts between the fed and unfed treatments. The notochord length on the day of parturition had a significant effect on the rate of change in length of cohorts of larvae in the fed treatment, indicating that cohorts of larvae born at larger sizes had slower rates of change in length than cohorts of smaller larvae. We did not observe differences in the rate of change in OGV between the fed and unfed treatments. However, in the fed treatment, larvae born at a larger size had a significantly slower rate of change in OGV than observed for smaller larvae. The difference may have been due to increased prey capture capabilities of larger larvae, allowing larvae to delay the use of their oil globule (Moodie et al. 1989); however, this was not explicitly tested in 
the present study. The observed slower rate of change in length of cohorts of larger larvae in the fed treatment and the similarity of the use of the oil globule between larval cohorts in the 2 treatments raises the question whether the prey concentrations and the nutritional quality of the food in the fed treatment were high enough to meet the energetic requirements of growing larvae. The time to $50 \%$ mortality was significantly longer in the fed treatment, indicating that food supply and quality may have been adequate to satiate larval survival for a limited time but not larval growth and development, as indicated by the slower rate of change in length of larger larvae.

When no food was present, the rate of change in length of cohorts of larvae was negative, indicating that the average length in a larval cohort declined over time, likely as a result of increased size-selective mortality among larger larvae within the cohort. However, the notochord length on the day of parturition did not affect the rate of change in length of cohorts of larvae in the unfed treatment. Similar results were reported by Garrido et al. (2015), who demonstrated that the mean size-at-age of cohorts of European sardine Sardina pilchardus larvae decreased over time when larvae were not fed, consistent with size-specific mortality. In an environment where food supply was limited, smaller larvae with a lower metabolic rate were thought to be favoured, due to their increased time to find adequate food (Bochdansky et al. 2005). In the present study, there was no relationship between the notochord length on the day of parturition and the rate of change in OGV in the unfed treatment. We hypothesized that because of the differences in the metabolic rate associated with larval length, larvae born at a larger size would use their oil globule at a faster rate than cohorts born at a smaller size in the unfed treatment. We speculate that smaller larvae may have invested some of the energy from the oil globule into growth in addition to metabolism and, therefore, no differences in the rate of change in volume of the oil globule between larval cohorts with different average lengths were found.

While the results of the present study highlight important relationships between maternal traits and larval characteristics and viability, there are several caveats to consider in interpreting some of our findings, based on the nature of laboratory experiments. Maternal sea perch were sampled from the Otago coast and transported to the laboratory. We do not know when the females were fertilized, the gestation time for this species is unknown, and the differences in holding time may have introduced variability in notochord length and OGV on the day of parturition.
Some females may have prolonged parturition due to stress experienced by the sampling method. More importantly, the gestation time could have varied due to variable temperature exposures or time without food among females. Larval notochord length and OGV could have been affected by varying temperature profiles experienced by the females; in particular, if the temperature was higher during the second half of the gestation period, the oil globule would have been used at a faster rate during larval development. Additionally, for short-term storage, larvae were preserved in formalin prior to measurements. Formalin can have a shrinking effect on larval length, which may have influenced the absolute value but not the overall trend in the rate of change in length of the notochord of cohorts of larvae in the present study. Due to the non-selective sampling method, i.e. hook and line fishing, we were only able to catch 1 very old female, and some of the results were influenced by this single individual. Nevertheless, the findings of the present study demonstrated that older, larger females were more fecund and provisioned their offspring with larger energy reserves, increasing their viability significantly compared to the larvae of younger, smaller females. These patterns highlight the importance of demographically based management strategies for ensuring reproductive viability of fish populations.

The present study provided evidence for the importance of the maintenance of older, larger females within a marine fish population for reproductive success. Older, larger female sea perch were more fecund and provisioned their larvae with larger oil globules, which increased survival and growth of larvae during the period of transitioning to exogenous feeding when food was not limited. They also produced cohorts of larvae with a broader range of notochord lengths, which may have important implications for the fitness of a larval cohort in an environment where prey and predator abundances are patchy and unpredictable. The present study adds valuable information to our knowledge of the reproductive biology and ecological advantages of older, larger females within subpopulations of sea perch specifically. Sea perch are a sedentary species, with little to no adult movement among distinct subpopulations. Dispersal in sea perch depends on the production of viable larvae and, therefore, the conservation of older, larger females may ensure the reproductive success of not only local subpopulations but also regional population networks.

The results of the present study add to the growing body of evidence that older, larger females play a key role in the reproductive success of marine fish populations. The common assumption that the total egg pro- 
duction is proportional to the $\mathrm{SSB}$, regardless of the age or size structure, may result in the mis-estimation of the reproductive potential in populations that show demographic differences in larval quality (Berkeley 2006). The present study supported the paradigm that factors other than the SSB may be important to the reproductive potential, and that only a small proportion of the population, namely older, larger females, may be responsible for recruitment success by producing more viable cohorts of larvae than younger, smaller females. The consideration of the age and size structure of a population in fisheries management measures may lead to increased reproductive potential (Spencer \& Dorn 2013). Marine protected areas and fishing closures have been successful tools to conserve the age and size structure of marine populations (Berkeley 2006, Jack \& Wing 2010). Our results provide a basis for the clear advantage of maintaining old-growth age distributions when managing sustainability of marine fish populations under changing environmental conditions and in the context of ecosystem-based management.

Acknowledgements. We thank Sorrel O'Connell-Milne, Rebecca McMullin, Clara Schlieman, Nichola Salmond, Erica Durante, Reuben Pooley, Bill Dickson, and Evan Kenton for assistance with field and laboratory work. We also thank 3 anonymous reviewers for comments on earlier versions of the manuscript. Technical support was provided by the Departments of Marine Science and the Portobello Marine Laboratory. S.K. and L.M.D. were supported by University of Otago doctoral scholarships. Funding support was provided by the National Science Challenge: Sustainable Seas (4.1.1 Ecosystem Connectivity) and from the University of Otago's Research Committee to S.R.W.

\section{LITERATURE CITED}

Anderson JT (1988) A review of size dependent survival during pre-recruit stages of fishes in relation to recruitment. J Northwest Atl Fish Sci 8:55-66

Aqui-S New Zealand LTD (2016) Aqui-S euthanasia: managing welfare during euthanasia. www.aqui-s.com/index. php/applications/euthanasia (accessed 20 August 2020)

Barneche DR, White CR, Marshall DJ (2018) Fish reproductive-energy output increases disproportionately with body size. Science 360:642-645

* Beddington JR, Agnew DJ, Clark CW (2007) Current problems in the management of marine fisheries. Science 316:1713-1716

Berkeley SA (2006) Pacific rockfish management: Are we circling the wagons around the wrong paradigm? Bull Mar Sci 78:655-668

Berkeley SA, Chapman C, Sogard SM (2004a) Maternal age as a determinant of larval growth and survival in a marine fish, Sebastes melanops. Ecology 85:1258-1264

Berkeley SA, Hixon MA, Larson RJ, Love MS (2004b) Fisheries sustainability via protection of age structure and spatial distribution of fish populations. Fisheries 29:23-32

* Birkeland C, Dayton PK (2005) The importance in fishery management of leaving the big ones. Trends Ecol Evol 20:356-358

Bobko SJ, Berkeley SA (2004) Maturity, ovarian cycle, fecundity and age-specific parturition of black rockfish. Fish Bull 102:418-429

Bochdansky AB, Grønkjær P, Herra TP, Leggett WC (2005) Experimental evidence for selection against fish larvae with high metabolic rates in a food limited environment. Mar Biol 147:1413-1417

* Botsford LW, Castilla JC, Peterson CH (1997) The management of fisheries and marine ecosystems. Science 277: 509-515

* Castro LR, Cowen RK (1991) Environmental factors affecting the early life history of bay anchovy Anchoa mitchilli in Great South Bay, New York. Mar Ecol Prog Ser 76: 235-247

Chambers RC, Leggett WC (1996) Maternal influences on variation in egg sizes in temperate marine fishes. Am Zool 36:180-196

Cowan JH, Houde ED, Rose KA (1996) Size-dependent vulnerability of marine fish larvae to predation: an individual-based numerical experiment. ICES J Mar Sci 53: 23-37

Cushing DH (1972) The production cycle and the numbers of marine fish. Symp Zool Soc Lond 29:213-232

* Dick EJ, Beyer SG, Mangel M, Ralston S (2017) A metaanalysis of fecundity in rockfishes (genus Sebastes). Fish Res 187:73-85

* Dower JF, Pepin P, Kim GC (2009) Covariation in feeding success, size-at-age and growth in larval radiated shanny (Ulvaria subbifurcata): insights based on individuals. J Plankton Res 31:235-247

* Durante LM, Beentjes MP, Wing SR (2020) Shifting trophic architecture of marine fisheries in New Zealand: implications for guiding effective ecosystem-based management. Fish Fish 21:813-830

Ferron A, Leggett WC (1994) An appraisal of condition measures for marine fish larvae. Adv Mar Biol 30:217-303

Fisher R, Sogard SM, Berkeley SA (2007) Trade-offs between size and energy reserves reflect alternative strategies for optimizing larval survival potential in rockfish. Mar Ecol Prog Ser 344:257-270

Furlani DM (1997) Development and ecology of ocean perch larvae, Helicolenus percoides (Richardson, 1842) (Pisces: Scorpaenidae), from southern Australian waters, with notes on the larvae of other sympatric scorpaenid genera. Mar Freshw Res 48:311-320

Garrido S, Ben-Hamadou R, Santos AMP, Ferreira S and others (2015) Born small, die young: intrinsic, size-selective mortality in marine larval fish. Sci Rep 5:17065

Graham DH (1939) Breeding habits of the fishes of Otago Harbour and adjacent seas. Trans Proc R Soc NZ 69: 361-372

Green BS (2008) Maternal effects in fish populations. Adv Mar Biol 54:1-105

Hempel G, Blaxter JHS (1967) Egg weight in Atlantic herring (Clupea harengus L.). ICES J Mar Sci 31:170-195

Hislop JRG (1988) The influence of maternal length and age on the size and weight of the eggs and the relative fecundity of the haddock, Melanogrammus aeglefinus, in British water. J Fish Biol 32:923-930

*Hixon MA, Johnson DW, Sogard SM (2014) BOFFFFs: On the importance of conserving old growth age structure 
in fishery populations. ICES J Mar Sci 71:2171-2185

Houde ED (1997) Patterns and trends in larval-stage growth and mortality of teleost fish. J Fish Biol 51:52-83

*Hsieh CH, Yamauchi A, Nakazawa T, Wang WF (2010) Fishing effects on age and spatial structures undermine population stability of fishes. Aquat Sci 72:165-178

* Huwer B, Clemmesen C, Grønkjær P, Köster FW (2011) Vertical distribution and growth performance of Baltic cod larvae - field evidence for starvation-induced recruitment regulation during the larval stage? Prog Oceanogr 91:382-396

Jack L, Wing SR (2010) Maintenance of old-growth size structure and fecundity of the red rock lobster (Jasus edwardsii) among marine protected areas in Fiordland, New Zealand. Mar Ecol Prog Ser 404:161-172

Johnson DW, Grorud-Colvert K, Sponaugle S, Semmens BX (2014) Phenotypic variation and selective mortality as major drivers of recruitment variability in fishes. Ecol Lett 17:743-755

Kjesbu OS (1989) The spawning activity of cod, Gadus morhua L. J Fish Biol 34:195-206

Lasker R (1975) Field criteria for survival of anchovy larvae: the relation between inshore chlorophyll maximum layers and successful first feeding. Fish Bull 73:453-462

Lawton RJ, Wing SR, Lewis AM (2010) Evidence for discrete subpopulations of sea perch (Helicolenus percoides) across four fjords in Fiordland, New Zealand. NZ J Mar Freshw Res 44:309-322

Leggett WC, Deblois E (1994) Recruitment in marine fishes: Is it regulated by starvation and predation in the egg and larval stages? Neth J Sea Res 32:119-134

Longhurst A (2002) Murphy's law revisited: longevity as a factor in recruitment to fish populations. Fish Res 56:125-131

Marshall CT, O'Brien L, Tomkiewicz J, Köster FW and others (2003) Developing alternative indices of reproductive potential for use in fisheries management: case studies for stocks spanning an information gradient. J Northwest Atl Fish Sci 33:161-190

Marteinsdottir G, Steinarsson A (1998) Maternal influence on the size and viability of Iceland cod Gadus morhua eggs and larvae. J Fish Biol 52:1241-1258

Miller TJ, Crowder LB, Rice JA, Marshall EA (1988) Larval size and recruitment mechanisms in fishes: toward a conceptual framework. Can J Fish Aquat Sci 45:1657-1670

Moodie GEE, Loadman NL, Wiegand MD, Mathias JA (1989) Influence of egg characteristics on survival, growth and feeding in larval walleye (Stizostedion vitreum). Can J Aquat Sci 46:516-521

Murdoch RC (1989) The effects of a headland eddy on surface macro-zooplankton assemblages north of the Otago Peninsula, New Zealand. Estuar Coast Shelf Sci 29: 361-383

Nikol'skii GV (1962) On some adaptations to the regulation of population density in fish species with different types of stock structure. In: Le Cren ED, Holdgate MW (eds) The exploitation of natural animal populations. Blackwell, Oxford, p 265-282

Park TJ (1994) Ocean perch, Helicolenus sp. In: Tilzey RDJ (ed) The south east fishery. A scientific review with particular reference to quota management. Bureau of Resource Sciences, Canterbury, p 237-246

Editorial responsibility: Craig Radford,

Warkworth, New Zealand

Reviewed by: 3 anonymous referees
Parrish RH, Mallicoate DL, Klingbeil RA (1986) Age dependent fecundity, number of spawners per year, sex ratio, and maturation stages in northern anchovy, Engraulis mordax. Fish Bull 84:503-517

Paul LJ, Francis MP (2002) Estimates of age, growth, and mortality parameters of sea perch (Helicolenus percoides) off the east coast of the South Island of New Zealand. Final Research Report for Ministry of Fisheries Research Project SPE2000/01. Ministry of Fisheries, Wellington

*Paul LJ, Horn PL (2009) Age and growth of sea perch (Helicolenus percoides) from two adjacent areas off the east coast of South Island, New Zealand. Fish Res 95:169-180

*Pikitch EK, Santora C, Babcock EA, Bakun A and others (2004) Ecosystem-based fishery management. Science 305:346-347

Roff DA (1992) The evolution of life histories: theory and analysis. Chapman \& Hall, New York, NY

Sasaki A, Ellner SP (1995) The evolutionarily stable phenotype distribution in a random environment. Evolution 49: 337-350

Secor DH (2000) Spawning in the nick of time? Effect of adult demographics on spawning behaviour and recruitment in Chesapeake Bay striped bass. ICES J Mar Sci 57 : 403-411

Sequeira V, Neves A, Vieira AR, Barros Paiva R, Canário A, Serrano Gordo L (2015) Estimating fecundity in the zygoparous species Helicolenus dactylopterus (Actinopterygii, Scorpaeniformes): adaptation of the gravimetric method. Hydrobiologia 758:211-222

Smith PJ, Struthers CD, Paulin CD, McVeagh SM, Daley RK (2009) Shallow genetic and morphological divergence among seaperches in the South Pacific (family Scorpaenidae; genus Helicolenus). J Fish Biol 74:1104-1128

Sogard SM, Berkeley SA, Fisher R (2008) Maternal effects in rockfishes Sebastes spp.: a comparison among species. Mar Ecol Prog Ser 360:227-236

* Spencer PD, Dorn MW (2013) Incorporation of weightspecific relative fecundity and maternal effects in larval survival into stock assessments. Fish Res, 138:159-167

Stevens CL, O'Callaghan JM, Chiswell SM, Hadfield MG (2019) Physical oceanography of New Zealand/Aotearoa shelf seas - a review. NZ J Mar Freshw Res, https://doi. org/10.1080/00288330.2019.1588746

Takagaki S (2016) The distribution and abundance of surface macro-zooplankton in the waters off the Otago coast. MSc thesis, University of Otago

Trippel EA, Kjesbu OS, Solemdal P (1997) Effects of adult age and size structure on reproductive output in marine fishes. In: Chambers C, Trippel EA (eds) Early life history and recruitment in fish populations. Chapman \& Hall Fish and Fisheries Series, Vol 21. Springer, Dordrecht, p 31-62

Vigliola L, Meekan MG (2002) Size at hatching and planktonic growth determine post-settlement survivorship of a coral reef fish. Oecologia 131:89-93

*Wright PJ, Gibb FM (2005) Selection for birth date in North Sea haddock and its relation to maternal age. J Anim Ecol 74:303-312

*Wright PJ, Trippel EA (2009) Fishery-induced demographic changes in the timing of spawning: consequences for reproductive success. Fish Fish 10:283-304

Submitted: November 6, 2019

Accepted: October 19, 2020

Proofs received from author(s): January 18, 2021 